\title{
Formation Mechanism of Precursor Films at High Temperatures: A Review
}

\author{
Qiaoli Lin*, Lu Liu and Wenqi Zhu
}

\begin{abstract}
The formation of a precursor film (PF) is always coupled with better wettability; thus, clarifying the formation mechanism is required to optimize the interfacial structures. However, recent research focuses on inert wetting systems at room temperature, which cannot guide practical material processing at high temperatures. In this review, PF formation mechanisms at high temperatures were reviewed. The mechanisms are surface diffusion, evaporation-condensation, subcutaneous infiltration, and rapid absorption and film overflow. In experimental metal/metal systems, the most probable mechanism is subcutaneous infiltration, related to the apparent contact angle, radius, and height of the gap between the substrate metal and the oxide film. The rapid absorption and film overflow mechanism usually occurs in metal/ceramic systems. The PF appearance for the adsorption mechanism must satisfy the paradox, that is, the relative inertial and high-affinity liquid/solid interface. Finally, another possible mechanism of PF appearance for the reactive wetting system at high temperatures was proposed, that is, the thin-surface transport mechanism. The PF formation is sensitive to external conditions. Therefore, it is necessary to develop thermodynamic and dynamic models for predicting and simulating PFs.
\end{abstract}

Keywords: Wettability, Wetting foot, Halo, Diffusing band

\section{Introduction}

A precursor film (PF) is a thin film that emanates from the three-phase contact-line region and spreads ahead of the latter at a significantly higher speed. In the literature, it is also called "halo" [1], "wetting foot" [2], and "diffusing band" [3]. Since Hardy first predicted and observed the existence of PFs [4], numerous theoretical and experimental studies have been conducted [5-8]. The molecularly thin film in the wetting of an organic fluid, even thinner, typically appears in hydrodynamic models for fixing the singularity between the slip length and the bulk drop [9]. Significant efforts have been made to detect thin films using ellipsometry, X-ray reflectometry, and interferometry techniques $[10,11]$. The related mechanisms have been clarified, mainly related to the Van der Waals disjoining pressure [12]. The categories of PFs are well

\footnotetext{
*Correspondence: Iqllinqiaoli@163.com

State Key Laboratory of Advanced Processing and Recycling

of Non-ferrous Metal, Lanzhou University of Technology, Lanzhou 730050, China
}

defined, such as adiabatic and diffusive films [11]. For a mesoscopic thick PF, it also satisfies hydrodynamics, even on a macroscopic scale [13]. However, the results obtained in these studies were aimed at inert wetting systems. Only a few studies were directly related to PFs in a reactive wetting system. In particular, for liquid metal systems, the properties of atomic fluids are significantly different from those of molecular fluids. Without the interaction of dispersion forces, the Van der Waals force in the liquid, the mass transition at the interface significantly improves because of thermal activation.

The pioneer work on PFs at high temperatures was reported by Radigan et al. [5] in 1974. For a viscous fluid (molten glass in their study) on metal, the authors believe that the spreading would be viscously resisted by the bulk cap of the liquid, and thus, a thin film with a height of $\sim 1 \mu \mathrm{m}$ can be formed. However, the interface remains inert. The mechanism of PF formation has not been clarified. A thickness in a molecular scale or higher typically corresponds to an inert formation mechanism. 
Although no specific definition was made based on the difference in thickness, the typical thickness of PFs for the non-inert (or reactive) formation mechanism is in the micron-scale order or lower. At high temperatures, this condition becomes complex. Metal/metal and metal/ ceramic couples are widely used. The intensive mass transition at the interface and the interfacial interactions are different from those of inert wetting systems at room temperature. For example, Singler et al. [13] found that $\mathrm{PFs}$ with segregated $\mathrm{Pb}$ and $\mathrm{Sn}$ alloy components were formed, owing to the composition gradients caused by the spreading sequence. Xian [14] reported that PF is an active adsorbed film on the micron scale, and only specific active elements can induce PF formation. Tanaka [15] observed $0.5 \mathrm{~nm}$ thick PF spreading ahead of the $\mathrm{AgCuTi}$ alloy on $\mathrm{SiC}$ at $1073 \mathrm{~K}$ and suggested that the diffusion of Ti atoms from molten $\mathrm{AgCuTi}$ alloys beyond the triple line generated the PFs. The mechanism of PF formation remains unclear. Wang et al. [16] investigated PF formation in reactive wetting systems for $\mathrm{Al}-\mathrm{Cu} / \mathrm{Ni}$ and $\mathrm{Al}-\mathrm{Ni} / \mathrm{Ni}$ couples using molecular dynamics simulation. They found that the PFs were suppressed by the dissolution reaction. Bredzs and Schwartzbart [17] reported that PF formation depended on the chemical composition of the substrate; in their study of a $\mathrm{Cu}$ /steel system, the PF width increased with the carbon concentration in the steel. In summary, almost no common regularity was observed. On the one hand, PFs can be a rate-limiting factor for bulk wetting; on the other hand, PF formation is always associated with excellent wettability. Therefore, revealing the formation mechanism is crucial for the fundamental theory and material process in the industry.

Based on the different interfacial interactions, two main categories of PF formation were focused on in this review: metal/metal systems and metal/ceramic systems. The interfacial interaction in metal/metal systems is typically stronger than in metal/ceramic systems. Although there are many types of ceramics, such as oxides, nitrides, borides, and carbides, the dominant chemical bonds are typically non-metallic. Therefore, in the following sections, we focus on these two categories.

\section{General Formation Mechanisms}

Generally, PFs in wetting systems at high temperatures should satisfy no significant mass transition at the liquid/solid interface; otherwise, PF formation will be suppressed. Based on this, the existing PF formation mechanisms can be summarized as follows:

1) In the surface diffusion mechanism, PFs are typically found in a viscous nonvolatile liquid. Spreading is based on the diffusion of the first (or thicker) molecular layer on the solid, as posited by Bascom et al.
[10], Cherry and Holmes [18], Blake and Haynes [19], and Ruckenstein and Dunn [20].

2) In the evaporation-condensation mechanism, PF formation requires the presence of a volatile liquid or condensable vapor. Spreading occurs because of the condensation of an absorbed film beyond the macroscopic triple line. This viewpoint was proposed by Hardy [4], who pioneered the observations in 1919.

3) In the subcutaneous infiltration mechanism proposed by Zhuang and Lugscheider [21], the liquid metal is sucked into the possible gap between the oxide film, owing to the capillary force. Thus, a thin film is formed beyond the triple line.

4) In the rapid absorption and film overflow mechanism proposed by Xian [14], the formation depends on the segregation of active addition beyond the macroscopic triple line. Thus, a portion of the liquid is attracted to form the PF.

The schematics for these mechanisms are shown in Figure 1.

The first two mechanisms are mainly controlled by a physical driving force, such as the disjoining pressure or surface tension gradient. As defined by de Gennes [7], the excess energy of a film on a substrate varies with the film thickness ( $\Delta e$ in Figure 1(a)). The disjoining pressure is the derivative of this energy, expressed as a function of thickness. When the excess energy is a decreasing function of the thickness (favoring a thick film), the disjoining pressure is positive, and the film is stable. Therefore, the difference in intermolecular forces between the liquid/liquid and liquid/solid interfaces may generate disjoining pressure gradients, owing to the film stability, forming the PF. The thickness may be thinner than one micron. Film propagation is typically controlled by the diffusion of such a thin layer on a solid substrate, as shown in Figure 1(a).

The factors that cause surface tension gradients might be the temperature gradients or the evaporation of a volatile component in the spreading direction. The temperature gradient factor is pellucid because surface tension is a temperature-dependent parameter. For evaporation of a volatile component, at least two effects are considered. One effect is the variation in the composition of the local zone, owing to the evaporation of the volatile component, which may induce a composition gradient in that local zone. It is known that surface tension also depends on the specific chemical composition. The other effect is that the condensed component on the solid surface beyond the triple line changes the surface energy of the solid and induces a tension gradient $[4,10,22-27]$. 

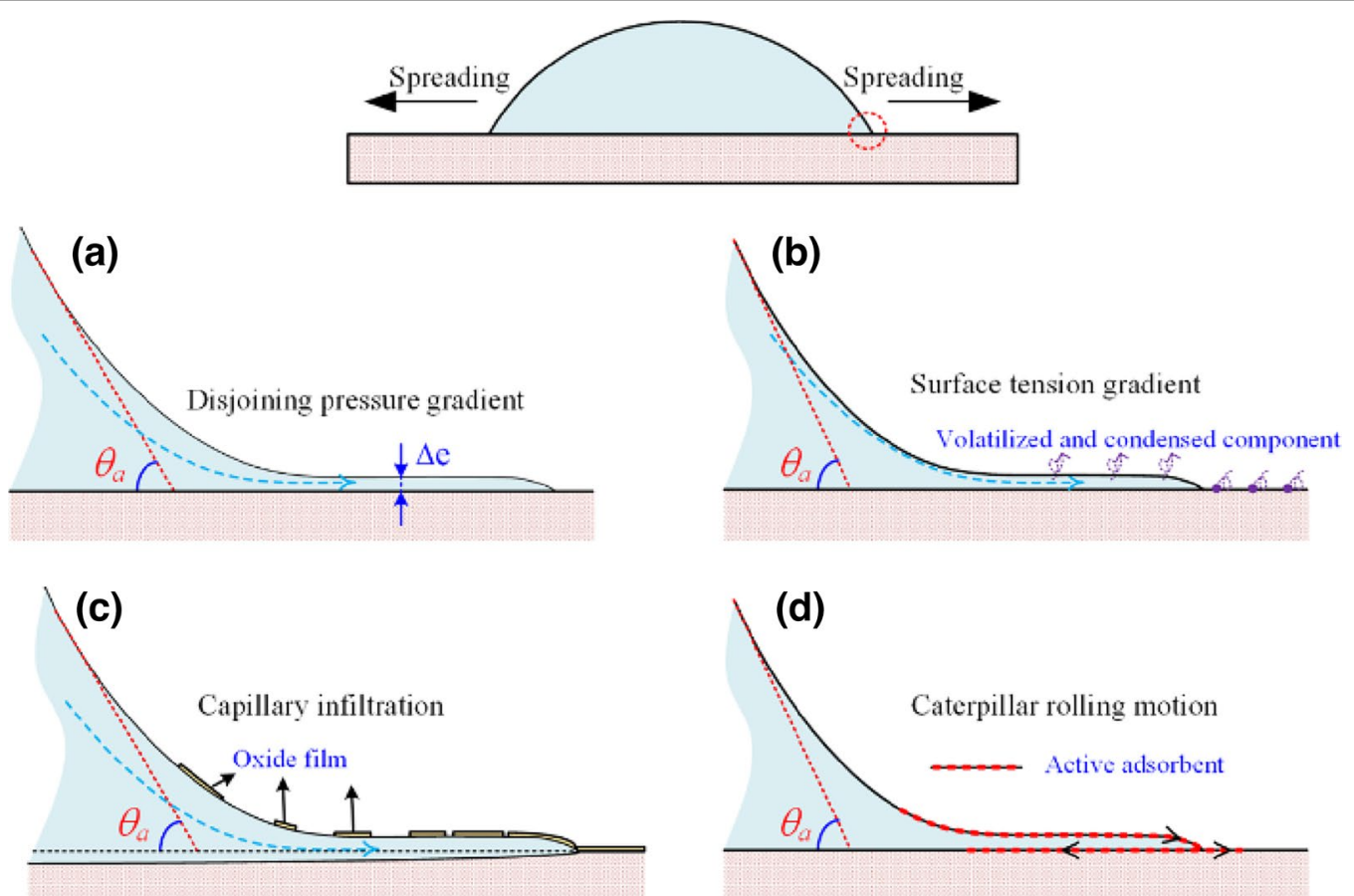

Figure 1 Schematics for (a) surface diffusion mechanism, (b) evaporation-condensation mechanism, (c) subcutaneous infiltration mechanism, and (d) rapid absorption and film overflow mechanism

\section{Precursor Films in Metal/Metal Couples}

The theories for identifying the mechanism governing the spreading behaviors of the first two mechanisms are satisfactory, both theoretical predictions and experimental observations. Both mechanisms are mainly based on the properties of the liquid. Moreover, the physical driving force typically corresponds to the organic fluid and the physical interaction at the interface. However, for some metallic systems, researchers have suggested that PF formation is related to the first two mechanisms. For example, in a $\mathrm{Zr}$-based alloy $\left(\mathrm{Zr}_{38.88} \mathrm{Ti}_{12.90} \mathrm{Cu}_{11.48} \mathrm{Ni}_{9.77} \mathrm{Be}_{23.97} \mathrm{Nb}_{3.00}\right)$ on the W surface at $1173 \mathrm{~K}, \mathrm{Li}$ et al. [28] found that the PF and the bulk melt were relatively independent of each other. Thus, they considered the spreading to be similar to that at room temperature. The PF length increased linearly with $t^{1 / 2}$. Hence, they consider that PF is generated through diffusion. In the wetting of $\mathrm{W}$ by $\mathrm{Zr}$-based alloys, the $\mathrm{W}$-oxides are volatilized because of the relatively high vapor pressure of $\mathrm{W}$-oxides at the test temperatures and atmosphere, and the oxide-free surface of $\mathrm{W}$ can be obtained. Moon et al. [29] observed the diffusion mechanism of metallic $\mathrm{PF}$ in $\mathrm{Pb} / \mathrm{Cu}$ and $\mathrm{Pb}-\mathrm{Bi} / \mathrm{Cu}$ systems. They reported that the macroscopic contact angle is insensitive to the temperature or composition within the investigated ranges. Although the oxide films on $\mathrm{Cu}$ may have influenced the results, the authors performed the tests in an ultrahigh vacuum environment using Ar ion-sputtering cleaning to minimize the effect of the oxide film. Molecular dynamic (MD) simulation for a metallic fluid on a solid metallic substrate also supports this mechanism [30]. As shown in Figure 2, the results for $\mathrm{Pb}$ on $\mathrm{Cu}$ ( $\left(\begin{array}{lll}1 & 1 & 1\end{array}\right)$ and $\left(\begin{array}{lll}1 & 0 & 0\end{array}\right)$ surfaces were obtained by Webb III

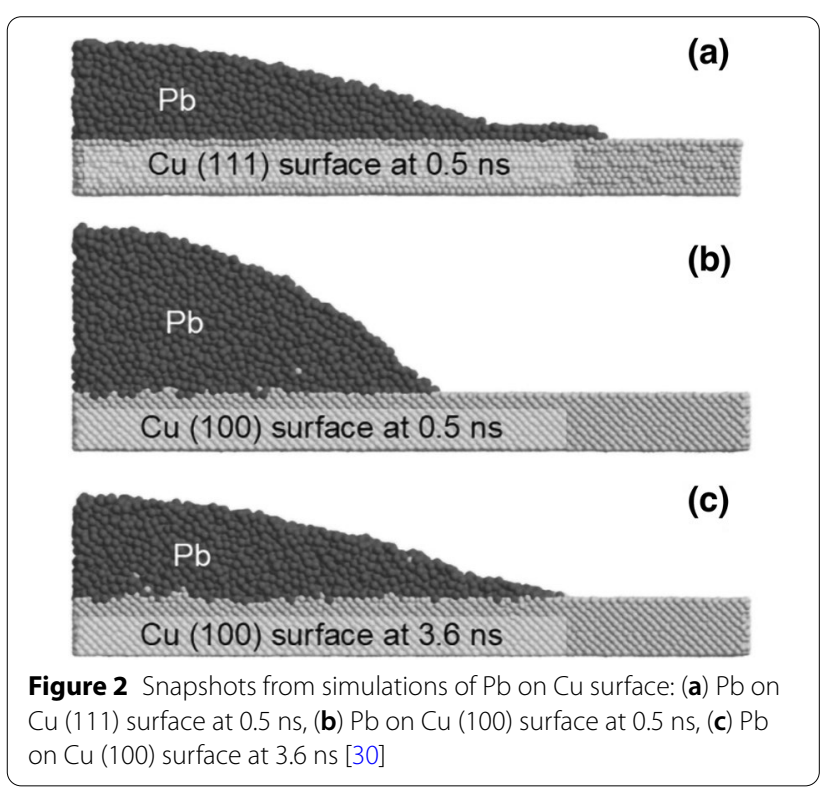


et al. [30]. The PF ( 2.6-2.8 $\AA$ in thickness) was formed ahead of the triple line during the spreading of $\mathrm{Pb}$ on the $\mathrm{Cu}\left(\begin{array}{lll}1 & 1 & 1\end{array}\right)$ surface and formed after the equilibrium state for $\mathrm{Pb}$ on the $\mathrm{Cu}\left(\begin{array}{lll}1 & 0 & 0\end{array}\right)$ surface. The variation in the PF contact radius over time followed a linear pattern for $R(t)-t^{1 / 2}$; thus, the surface diffusion mechanism was observed. However, from an experimental viewpoint, the ideal situation cannot proceed because of the inevitable effect of the oxide film on solid metals unless special methods have been applied during the experiment to obtain an oxide-free surface under an extremely low partial pressure of oxygen (for example, Ar ion-sputtering cleaning or in a dry- $\mathrm{H}_{2}$ atmosphere). Therefore, under nonideal or practical conditions, the formation of PFs in metallic systems tends toward the third mechanism.

\subsection{Precursor Films in Ideal (Oxide-Free) Systems}

Numerous studies have been conducted under ideal conditions based on MD simulations to investigate PF, usually found in metallic systems [31-41]. Typically, these systems are classified as nonreactive or reactive. Although Webb III et al. [30] claims that an atomistic PF, which extends in front of the triple line, can be observed in both reactive and nonreactive systems, PFs are more evident in nonreactive systems than in reactive systems.

For example, in the $\mathrm{Ag} / \mathrm{Cu}\left(\begin{array}{lll}1 & 0 & 0\end{array}\right)$ system (a reactive system), dissolution occurs when the couple is in contact. No PF with a certain width is formed beyond the triple line. In nonreactive couples (Table 1), PF is easily observed in the MD simulations. These researchers [30, $36,42-46]$ observed a significant effect of substrate orientation on PF formation. Even no oval shape of PF can be induced, owing to the different substrate orientation [44-46], as in Cu/W (1 0 0 $)$, Li/Fe $\left(\begin{array}{lll}1 & 1 & 2\end{array}\right)$, and $\mathrm{Li} / \mathrm{Cu}(1$ $10)$. However, most MD simulations of wetting systems have focused on the scaling law of $R(t) \sim t^{n}$ for both PF and the primary drop to reveal PF formation ahead of the primary drop. Generally, $R(t)$ for PF satisfies $R(t) \sim t^{1 / 2}$ $[30,32,34,37,38,43,47]$, whereas $R(t)$ for the primary drop satisfies $R(t) \sim t^{1 / 7}$. Exceptions exist for the drop that spreads with $R(t) \sim t^{1 / 2}$ for a PF and $R(t) \sim t^{4 / 5}$ for the primary drop and for a PF that spreads with $R(t) \sim t^{1 / 4}$ [43]. It should be noted that almost all PFs spread faster than the primary drop and thus can be ahead of the triple line. Web III et al. [30] further suggested that the spreading of the PF film may dominate wetting kinetics. To verify this viewpoint, they simulated the spreading of a Pd drop on a $\mathrm{Pb}$-prewetted $\mathrm{Cu}\left(\begin{array}{lll}1 & 0 & 0\end{array}\right)$ substrate (prewetted layer with a thickness of two atoms). Their results demonstrated that the presence of a prewetting film accelerated the spreading of the Pd drop. Although most MD simulations involved simple liquids (that is, pure metals), some systems with alloy drops or alloy substrates have also
Table 1 Liquid/solid couples in MD simulations with PF formation

\begin{tabular}{llllc}
\hline L/S systems & $\boldsymbol{\varepsilon}_{\mathrm{LL}}^{*}(\mathbf{k J} / \mathbf{m o l})$ & $\begin{array}{l}\boldsymbol{\varepsilon}_{\mathbf{L S S}}^{*} \\
(\mathbf{k J} / \mathbf{m o l})\end{array}$ & $\begin{array}{l}\boldsymbol{\varepsilon}_{\mathbf{S S}}^{*} \\
(\mathbf{k J} / \mathbf{m o l})\end{array}$ & $\begin{array}{l}\boldsymbol{\lambda}[\mathbf{5 4}] \\
(\mathbf{k J} / \mathbf{m o l})\end{array}$ \\
\hline $\mathrm{Pb} / \mathrm{Cu}[30]$ & -356 & -462 & -632 & 32 \\
$\mathrm{Ag} / \mathrm{Cu}$ (111) [32] & -510 & -562 & -632 & 9 \\
$\mathrm{In} / \mathrm{Cu}[39]$ & -460 & -548 & -632 & -2 \\
$\mathrm{Cu} / \mathrm{Ta}[40]$ & -632 & -1044 & -1472 & 9 \\
$\mathrm{Cu} / \mathrm{Mo}[41]$ & -632 & -1757 & -1200 & 75 \\
$\mathrm{Ag} / \mathrm{Mo}[41]$ & -510 & -1562 & -1200 & 148 \\
$\mathrm{~Pb} / \mathrm{Ni}[43]$ & -356 & -500 & -756 & 56 \\
$\mathrm{Li} / \mathrm{Cu}[44]$ & -294 & -481 & -632 & -18 \\
$\mathrm{Cu} / \mathrm{W}[45]$ & -632 & -1047 & -1642 & 90 \\
$\mathrm{Li} / \mathrm{Fe}[46]$ & -294 & -398 & -694 & 96 \\
$\mathrm{Ag} / \mathrm{Ni}[47]$ & -510 & -571 & -756 & 62 \\
$\mathrm{Li} / \mathrm{W}[55]$ & -294 & -781 & -1642 & 187
\end{tabular}

$\varepsilon_{\mathrm{LS}}^{*}=\left(\varepsilon^{*} \mathrm{LL}+\varepsilon^{*}{ }_{S S}\right) / 2+\lambda$

been investigated (for example, $\mathrm{Ag}-\mathrm{Cu} / \mathrm{Ni}$ [36], $\mathrm{AgCuTi} /$ $\mathrm{Cu}$ [48], $\mathrm{Al} / \mathrm{NiAl}$ [49], and $\mathrm{Al} / \mathrm{Ni}_{3} \mathrm{Al}$ [49]), and no PF formation mechanism was observed. Moreover, the number of atoms is very few in MD simulations (typically, $10^{6}$ atoms) compared with that in a typical experimental system $\left(\sim 10^{23}\right.$ atoms), which might cause the time scales for the spreading in MD simulations to be significantly below that in experimental nonreactive metallic wetting systems. The time takes nanoseconds or picoseconds for MD simulations but tens to hundreds of milliseconds for a practical system under existing experimental conditions (that is, an oxygen-free or reducing atmosphere) [50]. In these nonreactive metallic systems, the consensus points can be summarized as follows: the strong interaction at the interface, relatively weak interaction of the liquid, and high surface energy of the metallic substrate. Based on the relationship between the bond energy $(\varepsilon)$ and the heat of evaporation $\left(H_{\text {eva }}\right)$ (that is, $H_{\text {eva }}=-Z N_{\mathrm{a}} \varepsilon / 2$ [50], where $Z$ is the number of nearest neighbors in the bulk crystal, and $N_{\mathrm{a}}$ is the Avogadro constant), the bond energy can be obtained from $H_{\text {eva }}$ in terms of the molar unit, that is, assuming $\varepsilon^{*}=Z N_{a} \varepsilon$. The interaction characteristics of the metallic systems with PF formation, as indicated by the MD simulation, are presented in Table 1 . $\varepsilon_{\mathrm{LL}}^{*}, \varepsilon_{\mathrm{LS}}^{*}$ and $\varepsilon_{\mathrm{SS}}^{*}$ are the bond energy parameters for the liquid, liquid/solid interface, and solid, respectively. Almost all values of $\lambda$ are positive, where $\lambda$ is the interaction coefficient. A positive $\lambda$ value indicates that liquid and solid metals in the couple are thermodynamically repulsive and vice versa. Thermodynamic repulsion does not imply weak interfacial interactions. All absolute values of $\varepsilon_{\mathrm{LS}}^{*}$ are higher than $\varepsilon_{\mathrm{LL}}^{*}$, indicating that the interfacial interaction is stronger than the liquid. Moreover, this 
suggests that a contact angle below $90^{\circ}$ should be formed in these couples. Therefore, the strong interfacial interaction, relatively weak interaction of the liquid (or higher surface energy of the solid metal), and thermodynamic repulsion in the couple may combine to induce PF formation. Moreover, the couples listed in Table 1 are immiscible systems. Furthermore, the results may be predicted, and PFs would appear in similar immiscible systems, for example, $\mathrm{Pb} / \mathrm{Fe}, \mathrm{Pb} / \mathrm{Mo}, \mathrm{Sn} / \mathrm{Mo}, \mathrm{Ga} / \mathrm{Mo}, \mathrm{Ag} / \mathrm{Ta}$, In/Ta, $\mathrm{Ag} / \mathrm{V}, \mathrm{Ag} / \mathrm{W}$, and Au/W. Web III et al. [30], Benhassine et al. [41, 51], and Blake and De Coninck [52, 53] used the molecular kinetic theory (MKT) of wetting to fit MD simulation results. The results show that not only does the MKT fit the data, but the fitting has a physical interpretation and accurately depicts the dynamics. The MKT was developed by Eyring and coworkers of the absolute reaction rate theory. This theory focuses on the adsorption and desorption occurring at the microscopic and even atomic levels around the triple solid/liquid/vapor junction. In MD simulations of metallic systems, the PF may correspond to an adsorbed film ahead of the triple line. The formation mechanism may be closed but different from the fourth case depicted in Figure 1(d). Therefore, PFs may tend toward adsorbed films in metallic systems under ideal conditions; however, the exact formation mechanism of PF formation is still unclear.

\subsection{Precursor Films in Nonideal (Affected by Oxide Films) Systems}

The metallic surface of a substrate with high surface energy always adsorbs oxygen or any other gas in the air and forms a thin oxide film (typically on the nanoscale). This factor cannot be prevented even when noble metals, which are insensitive to oxygen, are used as substrates. For example, $\mathrm{Ag}$ forms $\mathrm{Ag}_{2} \mathrm{O}$, which reduces to $\mathrm{Ag}$ when the temperature exceeds $\sim 204{ }^{\circ} \mathrm{C}$ in the air [56]. Under common experimental conditions, for example, in a highvacuum atmosphere or a purified Ar atmosphere, the partial pressure of oxygen in the furnace generally ranges from $10^{-5}$ to $10^{-15} \mathrm{~Pa}$. The deoxidation (or dissociation) of the oxide film is difficult.

Generally, a metallic substrate with an oxide film causes PF formation in the third mechanism, that is, the subcutaneous infiltration mechanism. As reported in our papers on the wetting of mild steel, $\mathrm{Ti}$, and $\mathrm{Ti}$ alloys by $\mathrm{Al}$ alloys $[57,58]$, a thin film with a microscale thickness from the macroscopic triple line appears, as shown in Figures 3 and 4. At the experimental temperatures, the deoxidation of Fe-O oxide or Ti-O oxides occurs at an oxygen partial pressure as low as $10^{-15}$ or $10^{-39} \mathrm{~Pa}$. From the viewpoint of kinetic conditions, the loose structures of the Fe-O oxide film and the solid dissolution of oxygen from the Ti-O oxide film into the Ti matrix make

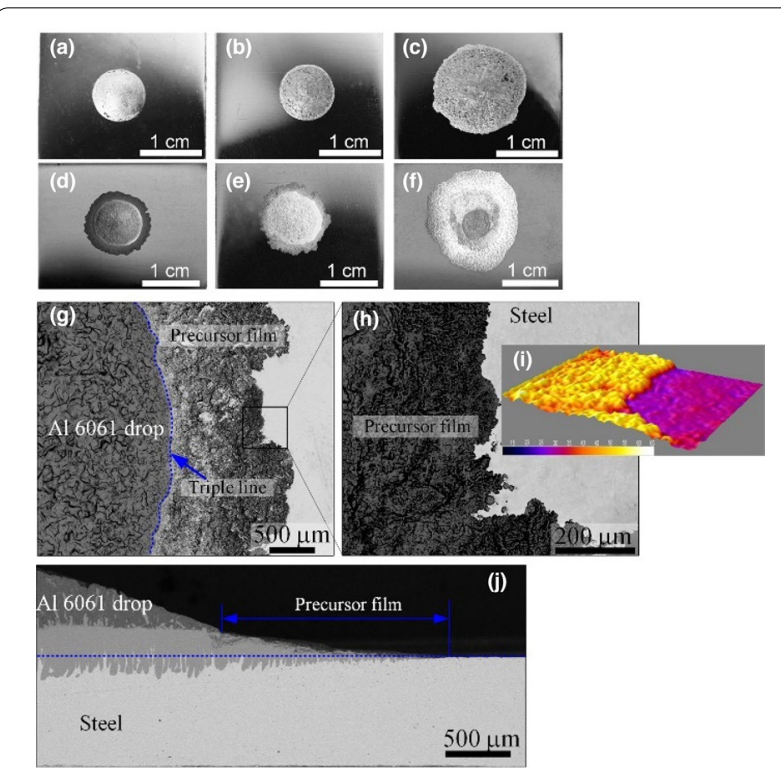

Figure 3 Appearance of representative sessile drop samples after wetting experiments in vacuum: (a)-(c) Al 4043 sample at 650, 700 , and $750{ }^{\circ} \mathrm{C} ;$ (d) $-(\mathbf{f}) \mathrm{Al} 6061$ sample at 600,650 , and $700^{\circ} \mathrm{C} ;$ (g) Top view at close of triple line for Al 6061 sample at $650^{\circ} \mathrm{C}$ and (h) details for edge of PF; (i) Three-dimensional reconstruction of PF; (j) Cross-sectional view of position at close of triple line for Al 6061 sample at $600^{\circ} \mathrm{C}$

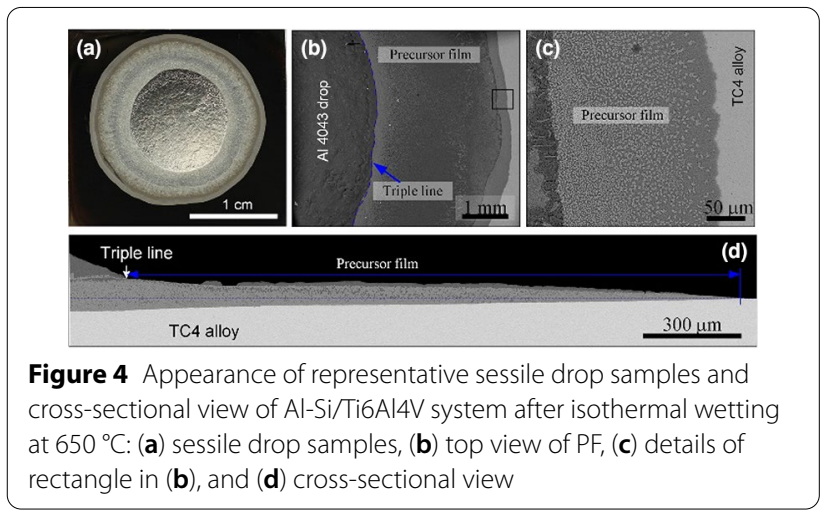

the oxide layer insufficient as a barrier to spreading. The macroscopic appearances of the mild steel after wetting by $\mathrm{Al}$ alloys at $600-750{ }^{\circ} \mathrm{C}$ are shown in Figure 3(a)-(f). The samples in the first row without an obvious PF correspond to the $\mathrm{Al}-\mathrm{Si}$ alloys in the couples. Compared to Al-Mg alloys in the wetting couples, the PF from the macroscopic triple line for the couples is significant after isothermal wetting at 600 and $650{ }^{\circ} \mathrm{C}$ (Figure $3(\mathrm{~g})-$ (j)). The PF in a reactive metallic system is an extended reaction layer. The typical characteristics of the PF in the reactive metallic system (that is, the $\mathrm{Al}-\mathrm{Si} / \mathrm{Ti} 6 \mathrm{Al} 4 \mathrm{~V}$ 
system) are shown in Figure 4. PF is an extended reaction layer, and similar results have been obtained for $\mathrm{AgCuTi} /$ Ti6Al4V [59], AgCu/Ti6Al4V [60], and SAC305/Cu systems [61]. Therefore, the characteristics that lead to PF formation in the subcutaneous infiltration mechanism are summarized as follows. First, the subcutaneous infiltration mechanism requires the existence of a thin film. Second, a sufficient gap and capillary force can suction the liquid metals. Third, the intrinsic final wettability is blocked by the oxide film. As detailed by the ideal schematic depicted in (Figure 5), the solid substrate dissolved in the liquid or the element in the liquid diffuses into the solid, inducing a variation in the substrate volume in the local contact area and creating a gap between the oxide film and the substrate metal.

When a liquid metal is suctioned into the gap, two issues must be considered: the condition in which the liquid permeates the gap and the distance (or length) that can be permeated. It is known that an oxide film induces poor wettability; the contact angle is denoted $\theta_{2}$ in Figure 5(b). The contact angle of the solid metal with the liquid metal is denoted $\theta_{1}$ in Figure 5(b). The driving force per distance $(d F / d x)$ can be expressed as follows [50]:

$$
\mathrm{d} F / \mathrm{d} x=\left(\sigma_{s l}-\sigma_{s v}\right)_{\text {metal }}-\left(\sigma_{s l}-\sigma_{s v}\right)_{\text {oxide }},
$$

where $\sigma_{s l}$ and $\sigma_{s v}$ are the interfacial tensions of solid/liquid and solid/vapor interfaces, respectively. Based on the equilibrium condition $(\mathrm{d} F / \mathrm{d} x=0)$ and by substituting this into Young's equation, a simple conclusion can be derived, that is $\theta_{1}+\theta_{2}=180^{\circ}$. The condition for the liquid to advance into the narrow slit is $\theta_{2}<180^{\circ}-\theta_{1}$. For a clean metallic surface, $\theta_{1}$ is typically lower than $50^{\circ}$, and the consequent permeation should satisfy $\theta_{2}<130^{\circ}$; thus, most oxide films can satisfy this condition. Generally, the contact angle should be lower than $90^{\circ}$ for permeation. In this case, a slit does not need to have a wettable surface or a nonwettable counterpart.

For the second issue, the distance $(D)$ can be analyzed using the capillary pressure equation:

$$
D \propto \Delta \mathrm{P}_{\mathrm{c}}=2 \sigma_{l v}\left(\cos \theta_{1}-\cos \theta_{2}\right) / h-\left(\sigma_{l v} \cos \theta_{a}+\sigma_{s l}\right) / 2 \pi R,
$$

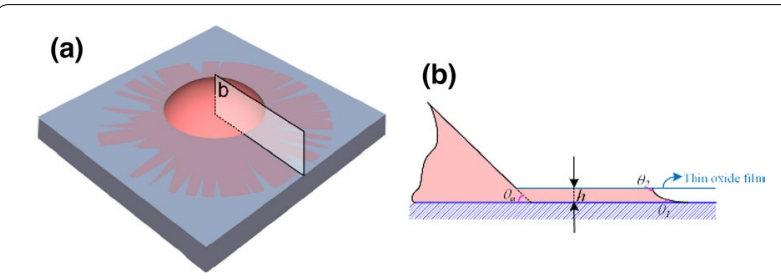

Figure 5 (a) Ideal schematic for subcutaneous infiltration mechanism and (b) cross-sectional view of (a) where $\Delta P_{\mathrm{c}}$ is the capillary pressure, $\theta_{a}$ is the apparent contact angle, $R$ is the contact radius of the primary drop, $h$ is the height of the gap between the surface couple, and $R \gg h$. For some systems, the permeation distance depends on $h, \theta_{a}$, and $R$. As expressed by Eq. (2), a decrease in $h$ increases $D$. A similar trend can be caused by an increase in $R$. Conversely, a decrease in $\theta_{a}$ decreases $D$, indicating that if the apparent contact angle is close to the intrinsic final wettability of the solid metal surface, PF formation in the subcutaneous infiltration mechanism will be suppressed further. However, some contradictions may be observed. An increase in $R$ decreases $\theta_{a}$ in the intrinsic final wettability. In actual situations, the influence of $R$ is more significant than $\theta_{a}$ when $R$ and $\theta_{a}$ simultaneously act on $D$. Thus, better wettability, compared to the wider PF, is usually observed. In reactive metallic systems, the permeated liquid reacts with the solid, and the intermetallics (IMCs) in the slit can precipitate and crack the oxide film [62]. However, substrate dissolution can provide a larger space for the permeation of a liquid metal. In other words, the surface capillaries (grain boundaries, where the large surface-area-to-volume ratio amplifies the dissolution effects) under the oxide film are enhanced [13]. The solid solution of the liquid metal in the solid substrate can also result in variation in the solid substrate volume, accelerating the oxide film cracking. Excessive dissolution of the substrate further suppresses PF formation [16]. The IMC precipitation process typically takes only dozens of milliseconds, comparable to the capillary penetration rate; however, it is significantly more rapid than oxide film cracking in advancing the triple line. The subcutaneous infiltration mechanism can also be observed for metal/ceramic systems, in which the ceramic is sensitive to oxygen, for example, in the reactive wetting of the $\mathrm{SiC}$ surface by molten $\mathrm{Ag}-\mathrm{Cu}$-Ti alloy. The authors observed a similar infiltration mechanism around the triple line in situ at an atomic scale using a high-resolution transmission electron microscope [63]. A thin amorphous layer ( 1-1.5 nm thick) on the (0006) plane of $\mathrm{SiC}$ was removed through the infiltration of the reactant, forming an extended reaction layer (that is, the $\mathrm{PF}$ ), as shown in Figure 6. Where the arrows denote the tip of the PF. Mass transfer in the film removes a surface amorphous layer.

\section{Precursor Films in Metal/Ceramic Couples}

Metal/ceramic systems, particularly oxide ceramics, without the effect of the oxide film, the mechanism is significantly different from that of metallic systems. In the wetting of oxide ceramics by Sn-based active solders, Xian [14] found that PFs always form together with improved wettability. The typical characteristics of the study can be summarized as follows [14]: PF formation is 

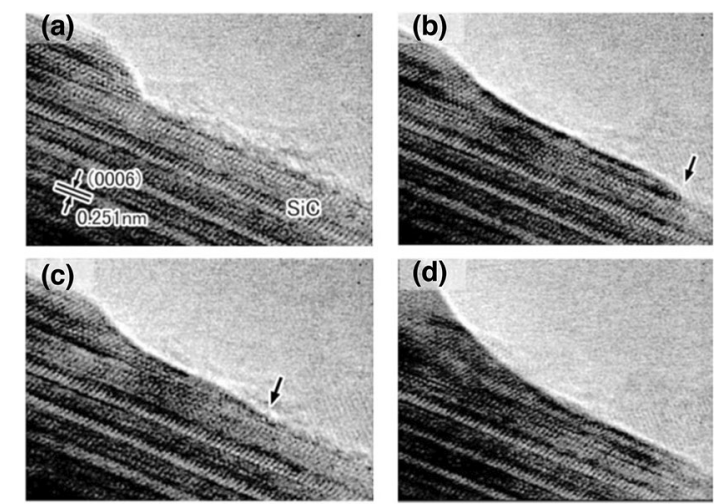

Figure 6 High-resolution images of tip of spreading molten alloy captured at approximately $800^{\circ} \mathrm{C}:$ (a) $0.0 \mathrm{~s}$, (b) $3.2 \mathrm{~s}$, (c) $4.4 \mathrm{~s}$, (d) $7.8 \mathrm{~s}$ [36]
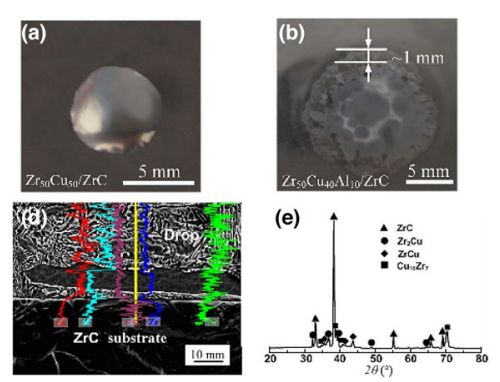

(f)

(f)
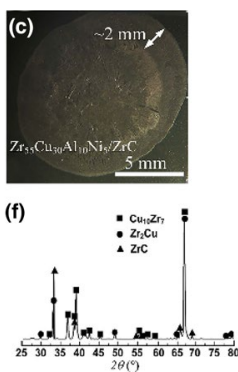

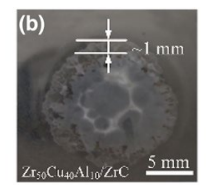

Figure 7 Top-view macrographs of solidified drops for (a) $\mathrm{Zr}_{50} \mathrm{Cu}_{50}$ l $\mathrm{ZrC}$, (b) $\mathrm{Zr}_{50} \mathrm{Cu}_{40} \mathrm{Al}_{10} / \mathrm{ZrC}$, and (c) $\mathrm{Zr}_{55} \mathrm{Cu}_{30} \mathrm{Al}_{10} \mathrm{Ni}_{5} / \mathrm{ZrC}$, (d) typical cross-sectional interface of $\mathrm{Zr}_{55} \mathrm{Cu}_{30} \mathrm{Al}_{10} \mathrm{Ni}_{5} / \mathrm{ZrC}$, and (e) and (f) $X$-ray diffraction results obtained for PFs in $\mathrm{Zr}_{50} \mathrm{Cu}_{40} \mathrm{Al}_{10} / \mathrm{ZrC}$ and $\mathrm{Zr}_{55} \mathrm{Cu}_{30} \mathrm{Al}_{10} \mathrm{Ni}_{5} / \mathrm{ZrC}$, respectively

related to the added active elements, such as $\mathrm{Ti}, \mathrm{Zr}$, and $\mathrm{Hf}$, but $\mathrm{V}, \mathrm{Nb}$, and Ta cannot trigger PF formation; PF formation is sensitive to the experimental temperature, substrate material, and specific composition of the solder. Moreover, Xian proposed three conditions: a fresh drop surface, specific transport rate of active addition, and specific interfacial reaction rate. Based on these assumptions, Xian proposed a rapid absorption and film overflow mechanism (Figure 1(d)). However, PF formation in metal/ceramic couples has not been sufficiently clarified.

The general characteristics of adsorption films have been refined further. In our previous study on the wetting of ceramics by Zr-based alloys [64-66], PF not only appeared in metal/oxide ceramic couples but also in metal/carbide ceramic couples (Figure $7(a)-(c)$ ). This case is different from the $\mathrm{Cu}-\mathrm{Ag}-\mathrm{Ti} / \mathrm{SiC}$ system. No visible reaction layer was found in $\mathrm{Zr}_{55} \mathrm{Cu}_{30} \mathrm{Al}_{10} \mathrm{Ni}_{5} / \mathrm{ZrC}$, indicating weak reactivity (Figure $7(\mathrm{~d})$ ). With the addition of $\mathrm{Al}$ and $\mathrm{Ni}$, the main compositions of the PF are almost invariant, corresponding to $\mathrm{Cu}-\mathrm{Zr}$ IMCs (as identified by the microarea X-ray diffraction in Figure 7(e) and (f)). In this case, the surface diffusion mechanism and evaporation-condensation mechanism can be excluded because of the more rapid diffusion rate of $\mathrm{Al}$ than $\mathrm{Cu}$ and $\mathrm{Zr}$ and the low vapor pressure at the experimental temperatures. The formation of the PF (or adsorption film) depends on interfacial interaction. A summary of the results of our previous studies is presented in Table 1. Improved wettability is accompanied by widened PFs, consistent with the findings of Xian [14]. Furthermore, weak interfacial reactivity for maintaining the relative inertia of the liquid/solid interface is an essential prerequisite. The positive or negative but close to zero Gibbs free energies per mole reactant $\left(\Delta G_{r}^{0}(1 \mathrm{~mol})\right)$ indicate weak interfacial reactivity (Table 1 ). For the metallic systems listed in Table 1 , refractory metals are the substrates, although the oxide film might affect the PF formation. As mentioned above, the oxides of these refractory metals exhibit high volatility in a high vacuum $\left(10^{-4} \mathrm{~Pa}\right)$ atmosphere, and the separate dripping method can eliminate the effect of the oxide film. Among these systems, the positive interaction coefficient $(\lambda)$ between the main composition $(\mathrm{Zr})$ and the refractory metal substrate indicates a weak interfacial interaction compared to reactive systems, and a higher positive value of $\lambda$ corresponds to a wider PF (Table 1). However, the nominal chemical bond energy between the main composition $(\mathrm{Zr})$ and refractory metal substrate $\left(\varepsilon_{Z r-s u b}^{*}\right.$ in Table 2; the higher negative value suggests a higher affinity or stronger interfacial interaction) indicates that PF formation should also satisfy the higher affinity than the liquid metal. The paradox, relative inertia, and strong interfacial interaction explain why the PF appearance is sensitive to the interfacial nature, temperature, and specific liquid metal composition. For example, the $\mathrm{PF}$ was on a very thin reaction layer ( $\mathrm{ZrC}$ layer) in $\mathrm{Zr}_{55} \mathrm{Cu}_{30} \mathrm{Al}_{10} \mathrm{Ni}_{5} / \mathrm{WC}$ [67], and the PF in $\mathrm{Zr}_{55} \mathrm{Cu}_{30} \mathrm{Al}_{10} \mathrm{Ni}_{5}$ / Mo was formed at only $1113 \mathrm{~K}$ [68] because of the relatively significant solid solubility of $\mathrm{Zr}$ in Mo when the temperature was raised, and the inertia of the liquid/solid interface deteriorated. For $\mathrm{Sn}-5 \mathrm{Ti}-x \mathrm{Me}(\mathrm{Me}=\mathrm{Ag}, \mathrm{Cu}$, and $\mathrm{Ni}$ ) on the surface of the Sialon ceramic [69], Me is within a specific concentration range that can enhance the PF or else would suppress the PF; this is because Ti in the alloys exists in a specific interfacial activity range to maintain the adsorption state. Moreover, the third addition changed the interfacial activity of Ti. Other elements in the same group, such as $\mathrm{Zr}$ and $\mathrm{Hf}$, also produce similar effects. The chemical adsorption at the interface always occurs before the precipitation of the reaction product. When the activity exceeds a critical value, the interfacial reaction accompanying the precipitation of the product breaks the adsorption state. 
Table 2 PF widths, contact angles, and thermodynamic parameters for various systems

\begin{tabular}{|c|c|c|c|c|}
\hline Metal/Metal system [64] & $\theta_{e}\left({ }^{\circ}\right)$ & Width & $\begin{array}{l}\lambda \\
(\mathrm{kJ} / \mathrm{mol})\end{array}$ & $\begin{array}{l}\varepsilon_{Z r-\text { sub }}^{*} \\
(\mathrm{~kJ} / \mathrm{mol})\end{array}$ \\
\hline $\begin{array}{l}\mathrm{Zr}_{55} \mathrm{Cu}_{30} \mathrm{Al}_{10} \mathrm{Ni}_{5} / \mathrm{Ta} \\
\text { at } 1113-1213 \mathrm{~K}\end{array}$ & 0 & $2 \mathrm{~mm}$ & 11 & -1317 \\
\hline $\begin{array}{l}\mathrm{Zr}_{55} \mathrm{Cu}_{30} \mathrm{Al}_{10} \mathrm{Ni}_{5} / \mathrm{Nb} \\
\text { at } 1113-1213 \mathrm{~K}\end{array}$ & $2-3$ & $1 \mathrm{~mm}$ & 4 & -1259 \\
\hline $\begin{array}{l}\mathrm{Zr}_{55} \mathrm{Cu}_{30} \mathrm{Al}_{10} \mathrm{Ni}_{5} / \mathrm{Mo}^{*} \\
\text { at } 1113-1213 \mathrm{~K}\end{array}$ & $4-7$ & $500 \mu \mathrm{m}$ & -25 & -1215 \\
\hline $\begin{array}{l}\mathrm{Zr}_{55} \mathrm{Cu}_{30} \mathrm{Al}_{10} \mathrm{Ni}_{5} / \mathrm{W} \\
\text { at } 1123-1173 \mathrm{~K}\end{array}$ & $4-11$ & $\sim 100 \mu \mathrm{m}$ & -36.5 & -1416 \\
\hline $\begin{array}{l}\mathrm{Zr}_{55} \mathrm{Cu}_{30} \mathrm{Al}_{10} \mathrm{Ni}_{5} / \mathrm{Fe} \\
\text { at } 1113-1213 \mathrm{~K}\end{array}$ & $14-24$ & 0 & -101.5 & -1015 \\
\hline Metal/Ceramic system & $\theta_{e}\left({ }^{\circ}\right)$ & Width & $\begin{array}{l}\Delta G_{r}^{0}(1 \mathrm{~mol}) \\
(\mathrm{kJ} / \mathrm{mol})\end{array}$ & \\
\hline $\begin{array}{l}\mathrm{Zr}_{55} \mathrm{Cu}_{30} \mathrm{Al}_{10} \mathrm{Ni}_{5} / \mathrm{ZrO}_{2} \text { [64] } \\
\text { at } 1133-1473 \mathrm{~K}\end{array}$ & $46-83$ & 0 & $\ll 0$ & \\
\hline $\mathrm{Zr}_{55} \mathrm{Cu}_{30} \mathrm{Al}_{10} \mathrm{Ni}_{5} / \mathrm{Y}_{2} \mathrm{O}_{3}[64]$ & $30-41$ & 0 & $\ll 0$ & \\
\hline $\begin{array}{l}\mathrm{Zr}_{55} \mathrm{Cu}_{30} \mathrm{Al}_{10} \mathrm{Ni}_{5} / \mathrm{SiO}_{2}[64] \\
\text { at } 1133-1253 \mathrm{~K}\end{array}$ & $32-50$ & 0 & $\ll 0$ & \\
\hline $\begin{array}{l}\mathrm{Zr}_{55} \mathrm{Cu}_{30} \mathrm{Al}_{10} \mathrm{Ni}_{5} / \mathrm{SiC}[64] \\
\text { at } 1133-1253 \mathrm{~K}\end{array}$ & 3 & 0 & $\ll 0$ & \\
\hline $\begin{array}{l}\mathrm{Zr}_{55} \mathrm{Cu}_{30} \mathrm{Al}_{10} \mathrm{Ni}_{5} / \mathrm{B}_{4} \mathrm{C} \text { [64] } \\
\text { at } 1133-1253 \mathrm{~K}\end{array}$ & 30 & 0 & -180.610 & \\
\hline $\begin{array}{l}\mathrm{Zr}_{55} \mathrm{Cu}_{30} \mathrm{Al}_{10} \mathrm{Ni}_{5} / \mathrm{TiC}[64] \\
\text { at } 1133-1253 \mathrm{~K}\end{array}$ & $10-14$ & 0 & -8.053 & \\
\hline $\begin{array}{l}\mathrm{Zr}_{55} \mathrm{Cu}_{30} \mathrm{Al}_{10} \mathrm{Ni}_{5} / \mathrm{WC}^{\#}[64] \\
\text { at } 1133-1253 \mathrm{~K}\end{array}$ & $11-19$ & $<100 \mu \mathrm{m}$ & -75.457 & \\
\hline $\begin{array}{l}\mathrm{Zr}_{55} \mathrm{Cu}_{30} \mathrm{Al}_{10} \mathrm{Ni}_{5} / \mathrm{Al}_{2} \mathrm{O}_{3}[64] \\
\text { at } 1133-1193 \mathrm{~K}\end{array}$ & 0 & $>100 \mu \mathrm{m}$ & -5.869 & \\
\hline $\mathrm{Zr}_{55} \mathrm{Cu}_{30} \mathrm{Al}_{10} \mathrm{Ni}_{5} / \mathrm{ZrC}[70]$ & 0 & $\sim 2 \mathrm{~mm}$ & 0 & \\
\hline $\mathrm{Zr}_{50} \mathrm{Cu}_{40} \mathrm{Al}_{10} / \mathrm{ZrC}[70]$ & 2 & $\sim 1 \mathrm{~mm}$ & - & \\
\hline $\mathrm{Zr}_{50} \mathrm{Cu}_{50} / \mathrm{ZrC}[70]$ & 14 & 0 & - & \\
\hline
\end{tabular}

*PF appearance only at an experimental temperature of $1113 \mathrm{~K}$; ${ }^{\mathrm{PFF}}$ above the $\mathrm{ZrC}$ reaction layer

For the wetting of graphite by $\mathrm{Cu}-20 \mathrm{Sn}-1 \mathrm{Cr}$ ternary alloys, we proposed another possible mechanism of PF formation, that is, the thin-surface transport mechanism [71]. In this case, it is a typical reactive system (Figure 8). A visible PF from the triple line can be observed in Figure $8(\mathrm{a})-(\mathrm{c})$. PF is an extended reaction layer, and this property is similar to the subcutaneous infiltration mechanism. However, no oxide film is affected in this case. The PF formed in this mechanism is also sensitive to the chemical composition. When the Sn concentration exceeds the critical value, the PF disappears; a typical couple $\left(\mathrm{Cu}-50 \mathrm{Sn}-1 \mathrm{Cr} / \mathrm{C}_{\text {graphite }}\right)$ is shown in Figure 8(e) and (e-1). Sn in $\mathrm{Cu}-20 \mathrm{Sn}-1 \mathrm{Cr}$ decreases the surface tension of the liquid, suggesting that $\mathrm{Sn}$ segregates to the surface. The surface tension of the molten $\mathrm{Cu}-20 \mathrm{Sn}-1 \mathrm{Cr}$ alloy was evaluated using the axisymmetric droplet shape analysis method, and the value was $\sim 855 \pm 25 \mathrm{mN} / \mathrm{m}$ at $1100{ }^{\circ} \mathrm{C}$ (Figure $8(\mathrm{f})$ ). Compared to the surface tension of pure copper at the melting point $(\sim 1303 \mathrm{mN} / \mathrm{m})$, the

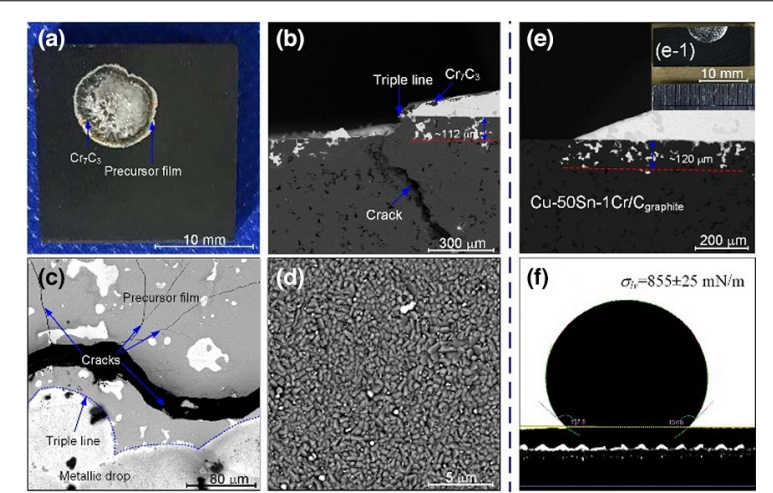

Figure 8 (a) Top view of macroscopic appearance for Cu-20Sn-1Cr/ $C_{\text {graphite }}$ after wetting, (b) Cross-sectional interfacial microstructures at close of triple line, (c) Top view of details at close of triple line, (d) Detailed microstructures of PF in (c), (e) microstructures at close of triple line and (e-1) Top view of macroscopic appearance for half of Cu-50Sn-1Cr/C graphite sample, (f) image of drop for surface tension evaluation 

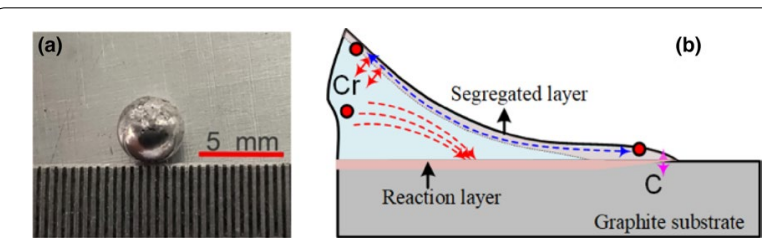

Figure 9 (a) Bead of Cu-20Sn-1Cr after arc melting, and (b) schematic of possible spreading mode

decrease in the surface tension by $\mathrm{Sn}$ is significant. As shown in Figure 9(a), the metallic bead of $\mathrm{Cu}-20 \mathrm{Sn}-1 \mathrm{Cr}$ after arc melting shows no copper color but a bright color, demonstrating $\mathrm{Sn}$ segregation during the alloying process. During the wetting process, the active addition of $\mathrm{Cr}$ segregates into the $\mathrm{Sn}$ segregated layer, owing to the difference in the chemical potential between $\mathrm{Cr}$ in liquid $\mathrm{Cu}$ and $\mathrm{Cr}$ in liquid $\mathrm{Sn}$. Cr in the thin liquid Sn film reacts with the graphite substrate and forms a reaction layer from the triple line (Figure 9(b)). Based on the analysis of spreading dynamics, the calculated diffusion rate of $\mathrm{Cr}$ in liquid is significantly higher than that without $\mathrm{Sn}$ [72], supporting the transport mechanism of the thin liquid film. Moreover, when the Sn concentration in the liquid increases, the thin Sn film disappears, and no PF is formed.

\section{Conclusions and Future Outlook}

1) The formation mechanisms of PF at high temperatures, that is, surface diffusion, evaporation-condensation, subcutaneous infiltration, and rapid absorption and film overflow mechanisms, were reviewed. Each mechanism has unique characteristics and formation conditions.

2) In experimental metallic systems, the most probable mechanism is infiltration under the oxide film (that is, the subcutaneous infiltration mechanism). The formation conditions, which are easily satisfied for a solid metal with an oxide film, are discussed. The permeated distance depends on the apparent contact angle, radius, and height of the gap between the substrate metal and oxide film.

3) In metal/ceramic systems, the most likely mechanism is an active adsorption film (that is, the rapid absorption and film overflow mechanism). The PF appearance must satisfy the paradox, that is, the relative inertia and high-affinity liquid/solid interface. This property is also suitable for oxide-free metallic systems, commonly observed in MD simulations.

4) Finally, we propose another possible mechanism for the appearance of $\mathrm{PF}$ in reactive wetting systems at high temperatures, that is, the thin-surface transport mechanism.

5) In future studies, additional experimental cases are required to comprehensively review the PF formation mechanism at high temperatures. All slight variations in experimental conditions may lead to the disappearance of PF or cause different formation mechanisms; thus, data collection should be handled cautiously. Based on further experiments, it will be possible to establish a thermodynamic model to describe the PF formation mechanism.

\section{Acknowledgements}

Not applicable.

\section{Authors' Contributions}

QL was responsible for all analyses and wrote the original version of the manuscript; LL assisted with data collection; WZ revised the final version of the manuscript. All authors have read and approved the revised manuscript.

\section{Authors' Information}

Qiaoli Lin, born in 1983, is currently a professor at Welding Technology and Engineering Department, Lanzhou University of Technology, China. He received his PhD degree from Jilin University, China, in 2011. His research interests include joining dissimilar materials and interfacial optimization.

Lu Liu, born in 1998, is currently a postgraduate student at Welding Technology and Engineering Department, Lanzhou University of Technology, China.

Wenqi Zhu, born in 1998, is currently an undergraduate student at Welding

Technology and Engineering Department, Lanzhou University of Technology,

China.

Funding

Supported by National Natural Science Foundation of China (Grant Nos. 52165044, 51665031).

\section{Competing Interests}

The authors declare that they have no competing interests.

Received: 25 February 2021 Revised: 11 November 2021 Accepted: 9 February 2022

Published online: 05 March 2022

\section{References}

[1] TA Siewert, RW Heine, M G Lagally. Brazing alloy spreading on steel. Welding Journal, 1978, 57: 31-37.

[2] B W Edmund, S G Gary, R H David. Precursor film controlled wetting of Pb on Cu. Physical Review Letters, 2003, 91 (23): 1-4.

[3] G L J Bailey, H C Watkins. The flow of liquid metals on solid metal surfaces and its relation to soldering, brazing, and hot-dip coating. J Inst Metals, 1951, 80: 57-75

[4] W III Hardy. The spreading of fluids on glass. Philosophical Magazine and Journal of Science, 1919, 38(223): 49-55.

[5] W Radigan, H Ghiradella, H L Frisch, et al. Kinetics of spreading of glass on fernico metal. Journal of Colloid and Interface Science, 1974, 49(2): 241-248.

[6] A Marmur, M D Lelah. The dependence of drop spreading on the size of the solid surface. Journal of Colloid and Interface Science, 1980, 78(1): 262-265.

[7] P G de Gennes. Wetting: Statics and dynamics. Reviews of Modern Physics, 1985, 57(3): 827-863.

[8] G F Teletzke, H D Davis, L E Scriven. How liquids spread on solids. Chemical Engineering Communications, 1987, 55(1-6): 41-82.

[9] D L Chung. Materials for electronic packaging. Boston: ButterworthHeinemann, 1995. 
[10] W D Bascom, R L Cottington, C R Singleterry. Dynamic surface phenomena in the spontaneous spreading of oils on solids. Contact Angles Wettability \& Adhesion, 1964: 355-379.

[11] M N Popescu, G Oshanin, S Dietrich, et al. Precursor films in wetting phenomena. Journal of Physics: Condensed Matter, 2012, 24(24): 1-51

[12] S Benilde. Thin liquid wetting films. Current Opinion in Colloid \& Interface Science, 2010, 15(5): 330-340

[13] T J Singler, J A Clum, E R Prack. Wetting dynamics of molten solder alloys on metal substrates. Journal of Electronic Packaging, 1992,144 128-134.

[14] A P Xian. Precursor film of tin-based active solder wetting on ceramics. Journal of Materials Science, 1993, 28(4): 1019-1030.

[15] SI Tanaka, C Iwamoto. Reactive wetting dynamics on $6 \mathrm{H}$-SiC surface with oxide layer. Advanced Materials Research, 2006, 11: 571-574.

[16] S Y Wang, S L Wang, Y R Yang, et al. High-temperature reactive wetting systems: Role of lattice constant. Chemical Engineering Science, 2019, 209: 115206

[17] N Bredzs, H Schwartzbart. Grain boundary penetration and base metal erosion of in high temperature brazing. Welding Journal, 1962, 41 (3): 129-145.

[18] B W Cherry, C M Holmes. Kinetics of wetting of surfaces by polymers. Journal of Colloid and Interface Science, 1969, 29: 174-176.

[19] T D Blake, J M Haynes. Kinetics of liquid-liquid displacement. Journal of Colloid and Interface Science, 1969, 30(3): 421-423.

[20] E Ruckenstein, C S Dunnc. Slip velocity during wetting of solids. Journal of Colloid and Interface Science, 1977, 59(1): 135-138.

[21] H Zhuang, E Lugscheider. High temperature brazing. Beijing: National Defense Industry Press, 1989. (in Chinese)

[22] G F Teletzke, L E Scriven, HT Davis. Gradient theory of wetting transitions. Journal of Colloid and Interface Science, 1982, 87(2): 55-571.

[23] V Ludviksson, E N Lightfoot. The dynamics of thin liquid films in the presence of surface tension gradients. Aiche Journal, 1971, 17(5): 1166-1173.

[24] D H Bangham, Z Saweris. The behavior of liquid drops and adsorbed films at cleavage surfaces of mica. Transactions of the Faraday Society, 1938, 34: 554-570.

[25] M D Lelah, A Marmur. Spreading kinetics of drops on glass. Journal of Colloid and Interface Science, 1981, 82(2): 518-525.

[26] Q Yuan, Y P Zhao. Precursor film in dynamic wetting, electrowetting, and electro-elasto-capillarity. Physical Review Letters, 2010, 104(24): 246101.

[27] G H Findenegg, S Herminghaus. Wetting: Statics and dynamics. Current Opinion in Colloid \& Interface Science, 1997, 2(3): 301-307.

[28] Z K Li, G F Ma, H M Fu. The spreading kinetics and precursor film characteristics of Zr-based alloy melt on W substrate. Materials Letters, 2013, 98 : 98-101.

[29] J Moon, S Garoff, P Wynblatt, et al. Pseudopartial wetting and precursor film growth in immiscible metal systems. Langmuir, 2004, 20(2): 402-408,

[30] E B Webb III, G S Grest, D R Heine. Precursor film controlled wetting of Pb on Cu. Physical Review Letters, 2003, 91(23): 236102.

[31] TP Swiler, R E Loehman. Molecular dynamics simulations of reactive wetting in metal-ceramic systems. Acta Materialia, 2000, 48(18-19): 4419-4424.

[32] TP Swiler. The role of liquid-substrate interactions on wetting in metallic embedded atom method systems. Acta Materialia, 2000, 48(20): 4775-4782.

[33] E B Webb III, G S Grest. Molecular dynamics simulations of reactive wetting. Scripta Materialia, 2002, 47(6): 393-398.

[34] J Moon, J Yoon, P Wynblatt, et al. Simulation of spreading of precursing Ag films on $\mathrm{Ni}$ (100). Computational Materials Science, 2002, 25(3): 503-509.

[35] Q Zhang, T Cagin, A van Duin, et al. Adhesion and nonwetting-wetting transition in the $\mathrm{Al}^{-}-\mathrm{Al}_{2} \mathrm{O}_{3}$ interface. Physical Review B, 2004, 69(4): 045423.

[36] E B Webb III, G S Grest, D R Heine, et al. Dissolutive wetting of Ag on Cu: A molecular dynamics simulation study. Acta Materialia, 2005, 53(11): 3163-3177.

[37] D R Heine, G S Grest, E B Webb III. Surface wetting of liquid nanodroplets: Droplet-size effects. Physical Review Letters, 2005, 95(10): 107801.

[38] E B Webb III, J Hoyt, G S. Grest, et al. Atomistic simulations of reactive wetting in metallic systems. Journal of Materials Science, 2005, 40(9): 2281-2286.
[39] A Kuboy, T Makino, D Sugiyama, et al. Molecular dynamics analysis of the wetting front structure in metal/metal systems. Journal of Materials Science, 2005, 40(9): 2395-2400.

[40] A Hashibon, A Y Lozovoi, Y Mishin, et al. Interatomic potential for the Cu-Ta system and its application to surface wetting and dewetting. Physical Review B, 2008, 77(9): 094131

[41] M Benhassine, E Saiz, A P Tomsia, et al. Nonreactive spreading at high-temperature revisited for metal systems via molecular dynamics. Langmuir, 2009, 25(19): 11450-11458.

[42] Timoshenko, V Bochenkov, V Traskine, et al. Anisotropy of wetting and spreading in binary $\mathrm{Cu}-\mathrm{Pb}$ metallic system: Experimental facts and MD modeling. Journal of Materials Engineering and Performance, 2012, 21(5): 575-584.

[43] F Qiu, M Wang, H G Zhou, et al. Molecular dynamics simulation of the wetting behavior of $\mathrm{Pb}$ droplet on Ni substrate. Acta Physica Sinica, 2013, 62(12): 120203. (in Chinese)

[44] X Chen, X Sun, H Deng, et al. The wetting properties of Li droplet on Cu surfaces: A molecular dynamics study. Computational Materials Science, 2016, 119: 114-119.

[45] X Lv, C Guan, Z Han, et al. The wetting characteristics of copper droplets on tungsten surfaces on atomic scale: A molecular dynamics simulation. Computational Materials Science, 2020, 174: 109487.

[46] C Zou, X Sun, C Xu, et al. Wetting characteristics of lithium droplet on iron surfaces in atomic scale: A molecular dynamics simulation. Computational Materials Science, 2018, 149: 435-441.

[47] Y Sun, E B Webb III. The atomistic mechanism of high temperature contact line advancement: Results from molecular dynamics simulations. Journal of Physics: Condensed Matter, 2009, 21(46): 464135.

[48] Y Yang, Y Liang, J Bi, et al. Spreading behavior of AgCuTi/Cu at elevated temperatures: A molecular dynamics study. Journal of Molecular Liquids, 2020, 319: 114332

[49] L Lin, S Hui, G Lu, et al. Molecular dynamics study of high temperature wetting kinetics for $\mathrm{Al} / \mathrm{NiAl}$ and $\mathrm{Al} / \mathrm{Ni}_{3} \mathrm{Al}$ systems: Effects of grain boundaries. Chemical Engineering Science, 2017, 174: 127-135.

[50] N Eustathopoulos, M G Nicholas, B Drevet. Wettability at High Temperatures. Oxford: Elsevier Press, 1999.

[51] M Benhassine, E Saiz, A P Tomsia, et al. Nonreactive wetting kinetics of binary alloys: A molecular dynamics study. Acta Materialia, 2011, 59(3): 1087-1094.

[52] J De Coninck, T D Blake. Wetting and molecular dynamics simulations of simple liquids. Annual Review of Materials Research, 2008, 38: 1-22.

[53] T D Blake, J De Coninck. Dynamics of wetting and Kramers' theory. Europe Physical Journal-Special Topics, 2011, 197(1): 249-264.

[54] A K Niessen, F R de Boer, R Boom, et al. Model predictions for the enthalpy of formation of transition metal alloys II. Calphad, 1983, 7(1): $51-70$.

[55] S Xu, X Fan, C Gu, et al. First principles and molecular dynamics study of Li wetting and diffusion on W surfaces. Journal of Nuclear Materials, 2020, 539: 152345.

[56] W E Garner, LW Reeves. The thermal decomposition of silver oxide. Transactions of the Faraday Society, 1954, 50: 254-260.

[57] Q Lin, P Jin, R Cao, et al. Reactive wetting of low carbon steel by Al 4043 and 6061 alloys at $600-750^{\circ} \mathrm{C}$. Surface \& Coatings Technology, 2016, 302: 166-172.

[58] Q Lin, F Li, P Jin, et al. Reactive wetting of TA2 pure Ti and TC4 alloy by molten Al 4043 alloy at 873-973 K. Vacuum, 2017, 145: 95-102.

[59] G Liu, Y Li, W Long, et al. Wetting kinetics and spreading phenomena of the precursor film and bulk liquid in the AgCuTi/TC4 system. Journal of Alloys and Compounds, 2019, 802: 345-354.

[60] X Yu, J Yang, M Yan, et al. Kinetics of wetting and spreading of AgCu filler metal over Ti-6Al-4V substrates. Journal of materials science, 2016, 51(24): 10960-10969.

[61] J Cheng, X Hu, S Li. Effects of the surface roughness on wetting properties and interfacial reactions between SAC305 solder and Cu substrate with Ni-W-P coating. Journal of Materials Science: Materials in Electronics, 2020, 31(18): 15086-15096.

[62] P Protsenko, A Terlain, VTraskine, et al. The role of intermetallics in wetting in metallic systems. Scripta Materialia, 2001, 45(12): 1439-1445.

[63] S I Tanaka, C Iwamoto. Nanoscale dynamic wetting and spreading of molten Ti alloy on 6H-SiC. Materials Science and Engineering: A, 2008, 495(1-2): 168-173. 
[64] X Zheng, P Shen, Q Lin, et al. Wettability and reactivity between $\mathrm{B}_{4} \mathrm{C}$ and molten $\mathrm{Zr}_{55} \mathrm{Cu}_{30} \mathrm{Al}_{10} \mathrm{Ni}_{5}$ metallic glass alloy. Materials Chemistry and Physics, 2009, 117(2-3): 377-383.

[65] P Shen, $X$ Zheng, $Q$ Lin, et al. Wetting of polycrystalline $\mathrm{a}-\mathrm{Al}_{2} \mathrm{O}_{3}$ by molten $\mathrm{Zr}_{55} \mathrm{Cu}_{30} \mathrm{Al}_{10} \mathrm{Ni}_{5}$ metallic glass alloy. Metallurgical and Materials Transactions A, 2009, 40(2): 444-449.

[66] P Shen, $D$ Zhang, $X$ Zheng. Wetting of polycrystalline $W$ by molten $\mathrm{Zr}_{55} \mathrm{Al}_{10} \mathrm{Ni}_{5} \mathrm{Cu}_{30}$ alloy. Materials Chemistry and Physics, 2009, 115(1): 322-327.

[67] Shen, X Zheng, $\mathrm{H}$ Liu. Wetting of WC by a Zr-base metallic glass-forming alloy. Materials Chemistry and Physics, 2013, 139(2-3): 646-653.

[68] $X$ Zheng. Wettability of metals and ceramics by $\mathrm{Zr}_{55} \mathrm{Cu}_{30} \mathrm{Al}_{10} \mathrm{Ni}_{5} \mathrm{BMG}$ forming liquid and their characteristics. Jilin University, 2010.

[69] A P Xian. Joining of sialon ceramics by Sn-5 at \% Ti based ternary active solders. Journal of materials science, 1997, 32(23): 6387-6393.

[70] Q Lin. Wettability and spreading dynamics of carbide ceramics by molten metals. Jilin University, 2011.

[71] Q Lin, F Yang, HY Yang, et al. Wetting of graphite by molten Cu- $x \mathrm{Sn}-y \mathrm{Cr}$ ternary alloys at 1373 K. Carbon, 2020,159: 561-569.

[72] B Daniel, R M John, E R Michael. Diffusion in copper and copper alloys part III. Diffusion in systems involving elements of group IA, IIA, IIIB, IVB, VB, VIB, and VIIB. Journal of Physical and Chemical Reference Data, 1975,

4(1): $177-250$

\section{Submit your manuscript to a SpringerOpen ${ }^{\circ}$ journal and benefit from:}

- Convenient online submission

- Rigorous peer review

- Open access: articles freely available online

- High visibility within the field

- Retaining the copyright to your article

Submit your next manuscript at $\boldsymbol{\nabla}$ springeropen.com 